\title{
Asma: El autocuidado guiado redujo los incidentes de asma respecto al manejo tradicional
}

A. Lahdensuo, T. Haahtela, T. Herrala et al. Randomised comparison of guided self management and traditional treatement of asthma over one year. BMJ 1996; 312:748-52

\section{Objetivo}

Comparar el autocuidado y el manejo tradicional del asma en pacientes ambulatorios con asma leve y moderada a lo largo de un año de seguimiento.

\section{Diseño}

Estudio multicéntrico, prospectivo, randomizado y simple ciego.

\section{Lugar}

Consultorios externos de neumonología, Finlandia.

\section{Pacientes}

Mayores de 18 años con asma leve y moderada, que hayan tenido variaciones del flujo pico matutino-vespertino $>$ al $15 \%$ en 2 días durante una semana en los últimos 6 meses; con flujos picos matutinos > a $250 \mathrm{lts} / \mathrm{mi}-$ nuto; que estuvieran utilizando budesonida inhalatoria en dosis de 400 a $1600 \mathrm{mg} /$ día o beclometasona inhalatoria en dosis de 500 a $2000 \mathrm{mg} /$ día en los últimos seis meses o más y que no hubieran recibido corticoides orales en el último mes.

\section{Intervención}

Se randomizaron 122 pacientes en 2 grupos. Al final del estudio se analizaron los resultados entre 56 pacientes del grupo autocuidado y 59 pacientes del grupo manejo tradicional. La intervención en el grupo de autocuidado consistía en educar sobre anatomía y fisiología respiratoria, causas de asma, función de las diferentes dro- gas utilizadas, técnicas de respiración y relajación e instrucción de la técnica de automonitoreo con mediciones del flujo pico, ajuste de la medicación antiinflamatoria y conductas a seguir según los resultados.

\section{Medición de resultados principales}

Se tomaron en cuenta el número de internaciones, consultas no programadas, ausentismo laboral, consumo de antibióticos y corticoides orales, y también se los combinó como "incidentes por asma". Se evaluaron también estudios funcionales respiratorios en las consultas de seguimiento y encuestas de calidad de vida durante el año de seguimiento.

\section{Resultados}

El número de internaciones fue bajo en ambos grupos y no se hallaron diferencias estadísticas significativas entre ambos. Todos los otros indicadores fueron significativamente mejores para el grupo autocuidado.

Riesgos relativos del grupo autocuidado: a) consultas no programadas: 0,53 (IC 95\% 0,29 - 0,96); b) ausentismo laboral: $0,47(0,24-0,92)$; c) consumo de antibióticos: 0,44 $(0,23-0,83)$; d) uso de corticoides orales $0,18(0,07-0,44)$; e) incidentes por asma: 0,32 (0,19-0,55). Los valores espirométricos se mantuvieron estables en ambos grupos durante todo el estudio. La encuesta de calidad de vida fue 8 puntos superior en el grupo autocuidado con un IC $95 \%$ de $2-15$ puntos.

\section{Conclusiones}

Los pacientes que reciben educación en técnicas de autocuidado tienen menor número de incidentes por asma y mejor calidad de vida.

Financiación: Laboratorio Astra

\section{Comentario}

La idea de realizar este trabajo se basa en la intención de aclarar la controversia que hay en la literatura médica sobre la eficacia y utilidad de recomendar a los pacientes con asma leve y moderada medidas de autocuidado. Los grupos eran demográfica y clínicamente comparables. Se destaca que la medicación que utilizaron en el estudio no fue igual en ambos grupos. Los 56 pacientes del grupo autocuidado utilizaron budesonida inhalatoria en polvo seco administrado con turbuhalers, mientras que en el grupo tradicional 43 pacientes utilizaron budesonida inhalatoria en polvo seco administrado con turbuhalers, 10 budesonida inhalatoria con aerocámara y 6 beclometasona inhalatoria con aerocámara. El resto de las me- dicaciones para el asma eran similares. El estudio randomizado trata de asegurar que la única diferencia entre los grupos que se comparan sea la intervención que uno está evaluando. En este estudio no queda aclarado por qué motivo el grupo randomizado a la rama autocuidado recibió budesonida en forma inhalatoria en polvo seco en su totalidad mientras que el grupo manejo tradicional solo recibieron esta forma de medicación el $73 \%$ de los pacientes. Si bien este punto no invalida el trabajo no queda claro cuánto influyen en los resultados las diferencias en la medicación recibida en cada grupo. El hecho de no hallar diferencias en el número de internaciones probablemente se deba a una falta de poder del estudio para demostrarlas, ya que es un evento infrecuente en pacientes con asma leve y moderada. En todos los estudios que comparen intervenciones es importante incluir mediciones de calidad de vida. A pesar de las limitaciones mencionadas, este estudio respalda la práctica del autocuidado en nuestros pacientes, aunque esta estrategia haya sido cuestionada en otros estudios (1).

\section{Dr Pablo Jinich Unidad de Medicina Familiar y Preventiva} Hospital Italiano de Buenos Aires

1. Grampian Asthma Study of Integrated Care (GRASSIC). Effectiveness of routine self monitoring of peak-flow in patients with asthma.BMJ 1994, 308:564-7. 